\title{
Çok yönlü omuz instabilitesinde cerrahi teknikler ve klinik sonuçları
}

\section{Surgical techniques and clinical outcomes in multidirectional shoulder instability}

\author{
Ali Erşen ${ }^{1}$, Koray Şahin ${ }^{2}$ \\ ${ }^{1}$ İstanbul Üniversitesi İstanbul Tıp Fakültesi, Ortopedi ve Travmatoloji Ana Bilim Dalı, İstanbul \\ ${ }^{2}$ Muş Devlet Hastanesi, Ortopedi ve Travmatoloji Kliniği, Muş
}

\begin{abstract}
Çok yönlü (multidireksiyonel) omuz instabilitesi omuzda birden fazla yöne dislokasyonun olduğu, travma öyküsünün olmadığı veya minimal travma öyküsünün eşlik ettiği bir klinik tablodur. Çok yönlü omuz instabilitesi kompleks bir patoanatomiye sahiptir; gevşek bir glenohumeral kapsül ve artmış eklem hacmiyle karakterizedir. Klinik belirtilerdeki belirsizlik, belirgin olmayan travma öyküsü ve multifaktöriyel etiyolojisi nedeniyle tanısal anlamda ortopedi ve travmataloji doktorları için büyük zorluk oluşturmaktadır. Genel kabul gören terapötik yaklaşım konservatiftir ve hastaların büyük çoğunluğunda rehabilitasyonla iyi sonuçlar elde edilmektedir. Ancak uygun rehabilitasyona rağmen semptomatik olan hastalarda cerrahi müdahale gerekli olabilmektedir. Bu hastalarda tarihsel olarak uygulanan açık inferior kapsüler kaydırma ameliyatıyla iyi sonuçlar elde edilmiştir. Ancak son yıllarda ilerleyen artroskopik teknikler bu alanda yer etmiş, rehabilitasyona yanıt vermeyen vakalarda uygulanan, daha az invaziv olan artroskopik kapsüler plikasyon prosedürüyle beraber açık cerrahi ile benzer sonuçlar elde edilmiştir.
\end{abstract}

Anahtar sözcükler: omuz instabilitesi; çok yönlü omuz instabilitesi; açık inferior kapsüler kaydırma; artroskopik kapsüler plikasyon
Multidirectional instability of the shoulder (MDI) is a clinical condition in which there is a dislocation of the shoulder in more than one direction, without a history of trauma or accompanied by a minimal trauma. Multidirectional instability has a complex pathoanatomy. It is characterized by a redundant glenohumeral capsule and increased joint volume. Subtle clinical presentation, unclear trauma history and multifactorial etiology pose a great challenge for orthopedics and traumatology surgeons in terms of diagnosis. Generally accepted therapeutic approach is conservative and the majority of patients achieve good results with rehabilitation. However, in patients who are symptomatic despite appropriate rehabilitation, surgical intervention may be necessary. Good results have been obtained with open inferior capsular shift surgery, which has historically been performed in these patients. However, in recent years, advanced arthroscopic techniques have taken place in this field, and similar results compared to open surgery have been obtained with the less invasive arthroscopic capsular plication procedure, which is applied in cases that do not respond to rehabilitation.

Key words: shoulder instability; multidirectional shoulder instability; open inferior capsular shift; arthroscopic capsular plication $r^{2}$ ok yönlü (multidireksiyonel) omuz instabilitesi (ÇYOi, MOi) ilk olarak Neer ve Foster tarafından travmanın eşlik etmediği veya minimal travma sołึrası gelişen, omzun birden fazla yöne doğru instabilitesi olarak tanımlanmıştır. ${ }^{[1]}$ Takip eden yıllarda çYoi için farklı tanımlamalar yapılmaya çalışıımış olsa da literatürde bu patoloji için hâla bir görüş birliği oluşturulamamıştır. Bu nedenle Neer ve Foster tarafından yapılmış olan tanım hâlen çoğunlukla en geçerli tanım olarak kabul edilmektedir. Çok yönlü omuz instabilitesinin tanımlanmasından günümüze kadar geçen sürede temel bilimler, omuz biyomekaniği ve klinik konseptlerdeki ilerlemeler sayesinde glenohumeral eklem stabilitesi daha iyi anlaşılmıştır. Ancak ÇYoi, tanı ve tedavi açısından günümüzde ortopedi ve travmatoloji uzmanları için halen büyük bir zorluk oluşturmaktadır. Bu zorluğun en büyük sebebi ise glenohumeral eklem stabilitesinin kendine özgü olan kompleks yapısıdır.

\section{BIYOMEKANIK VE PATOANATOMI}

Çok yönlü omuz instabilitesinin tedavisi her hasta için anamnez ve fizik muayene sonrasında bireysel olarak planlanmalıdır. Cerrahi kararın verilmesi ve uygulanacak cerrahinin seçiminde glenohumeral eklem biyomekaniğinin bilinmesi, mevcut instabilitenin patoge-

İletişim / Contact: Doç. Dr. Ali Erşen • E-posta / E-mail: ali.ersen@istanbul.edu.tr

ORCID iD: Ali Erşen, 0000-0001-6241-2586 • Koray Şahin, 0000-0002-4759-4729

Geliş / Received: 26 Aralık 2021 • Kabul / Accepted: 31 Ocak 2022 
nezi ve anatomik lezyonların anlaşılması büyük önem taşımaktadır. Glenohumeral eklem stabilitesi statik ve dinamik komponentler olmak üzere temel olarak iki bileşenin ortak etkisiyle sağlanmaktadır. Statik stabilizatörler glenoid versiyonu ve konkavitesi ile labral yapılar ve glenohumeral bağlardan oluşurken dinamik stabilizatörler skapulotorasik kaslar, rotator manşet, eklem propriyosepsiyonu ve nöromusküler kontrol olarak bilinmektedir. Çoğu zaman bu stabilizatörlerin bir kısmının defektli olduğu durumlarda diğer komponentlerin kompansasyonu sayesinde stabilite korunabilmektedir. "Fonksiyonel stabilite" adı verilen bu konsepte göre normal bir omuzda stabilizasyonun korunması, stabilizasyondan sorumlu olan bu farklı mekanizmaların omuz hareketi esnasında koordineli çalışmasıyla ve hareketi oluşturan kas yapılarının aktivasyonuna eşlik ederek rotator manşetin sağladığı konkavite-kompresyon mekanizmasının korunması, skapulotorasik kasların etkisiyle skapula ve dolayısıyla glenoidin uzayda doğru konum ve versiyonda konumlanması ve nöromusküler propriyosepsiyon kontrolüyle sağlanmaktadır. ${ }^{[2-4]}$ Çok yönlü omuz instabilitesi bulunan hastalarda çoğunlukla statik ve dinamik mekanizmalarda aynı anda bozulma olduğu görülmüştür. Nadiren sadece dinamik stabilizatör mekanizmalarda değişiklik olan vakalar olmakla birlikte izole statik stabilizatör mekanizma defektine rastlanmamıştır. ${ }^{[5]}$

\section{CERRAHI TEDAVI}

Çok yönlü omuz instabilitesinin tedavisinde ilk yaklaşım tüm hastalar için konservatif rehabilitasyondur. ${ }^{[6-8]}$ Rehabilitasyonun hedefi periskapular kasların ve rotator manşet kaslarının güçlendirilmesiyle propriyosepsiyon eğitimi yapılması, böylece bozulmuş dinamik stabilizasyon mekanizmalarının tekrar kazanılarak hastanın omuz üzerine aktif kontrolünü tekrar elde etmesini sağlamaktır. ${ }^{[9,10]}$ Hastaların büyük çoğunluğu rehabilitasyona olumlu yanıt vermekte ve iyi sonuçlar elde edilmektedir. Nyiri ve ark. tarafından yapılmış olan bir biyomekanik çalışmada ise ÇYOI'li hastalarda fizik tedavinin tek başına bozulmuş omuz kinematiğinin kazanılmasında yeterli olmadığı gösterilmiştir. ${ }^{[11]}$ Buna ek olarak, rehabilitasyonun başarılı olmadığı hastalarda normal kas aktivitesinin elde edilmesi için cerrahinin gerekli olabileceği gösterilmiştir. ${ }^{[12,13]}$ Sonuç olarak günümüzde kabul edilen yaklaşım cerrahi girişimin yalnızca uygun rehabilitasyon programına rağmen semptomların devam ettiği sınırlı bir hasta grubu için düşünülmesi gerektiğidir. Özellikle istemli (volonter) dislokasyonu olan hastalarda, psikiyatrik patoloji mevcudiyetinde ve cerrahiye uyum gösteremeyeceği düşünülen genç hastalarda cerrahi tedaviden kaçınılmalıdır. ${ }^{[14]}$
Cerrahi tedavi hastanın semptomu ve instabiliteye neden olduğu düşünülen anatomik sebebe yönelik olarak bireyselleştirilmelidir. Çok yönlü omuz instabilitesinin cerrahi tedavisinde çok sayıda cerrahi teknik tanımlanmıştır. Rekonstrüktif teknikler arasında glenoid osteotomisi, labral augmentasyon ve kapsüloligamentöz rekonstrüksiyon prosedürleri gösterilebilir. Günümüzde en sık kullanılan teknikler ise kapsüloligamentöz rekonstrüksiyon teknikleri olan açık inferior kapsüler shift (kaydırma) ve artroskopik plikasyon teknikleridir. ${ }^{[4]}$

\section{AÇIK INFERIOR KAPSÜLER SHIFT (KAYDIRMA)}

Açık inferior kapsüler shift prosedürü Neer tarafından tanımlanmıştır ${ }^{[1]}$ ve artroskopik tekniklerin ilerleyip yaygınlaştığı 1990'lı yılların sonuna kadar ÇYOI'nin cerrahi tedavisinde altın standart yöntem olarak yaygın bir şekilde kullanılmıştır. ${ }^{[15]}$ Günümüzde artroskopik teknikler daha yaygın olarak uygulansa da açık inferior kapsüler shift prosedürünün uzun dönem takiplerde iyi sonuçları olduğu bildirilmiștir ${ }^{[15-17]}$ ancak ÇYOI'nin tedavisinde açık veya artroskopik tekniklerden hangisinin en iyi seçenek olduğu halen net olarak cevaplanamamıştır.

Bu prosedürdeki amaç inferior kapsülün plikasyonunu gerçekleştirerek anterior, inferior ve posterior kapsüler hacimde azalma elde etmektir. Anestezi altında yapılan detaylı bir muayenenin ve instabilite yönünün belirlenmesinin ardından hasta şezlong (beach-chair) pozisyonunda hazırlanır. Korakoid çıkıntıdan aksillaya uzanan yaklaşık 7-8 cm'lik bir insizyon yapılarak deltopektoral yaklaşımla cilt ve cilt altı dokular geçilir. Deltoid ve pektoralis majör kasları bulunur, sefalik ven ekarte edildikten sonra konjoint tendon ortaya konur ve mediale ekarte edilir. Orijinal teknikte tarif edildiği gibi subskapularis kası tam bir vertikal tenotomi ile kaldırılabileceği gibi anterior sirkumfleks vasküler yapıları korumak ve aksiller sinir yaralanması intimalini azaltmak için "L" şeklinde bir tenotomi yapılarak da kaldırılabilir. ${ }^{[18]}$ Ameliyat sonrası dönemde subskapularis yetmezliği olması veya subskapularis tenotomisinin skarlaşarak iyileşmesine bağlı olarak da gelişebilecek dış rotasyon kısıtıılı̆ı ihtimalini azaltmak için daha az invaziv bir yaklaşımla subskapularis kası, kas liflerine paralel şekilde split olarak geçilebilir. ${ }^{[19]} \mathrm{Bu}$ işlem subskapularis kasının üst 2/3 ile alt $1 / 3$ lifleri arasından, kas-tendon bileşkesinden biseps tendonu uzun başının medial sınırına kadar yapılmalıdır. Ardından künt disseksiyonla kapsül ortaya konur. Kapsüler insizyon "T" şeklinde, Neer ve Foster tarafından tarif edildiği gibi "T"'nin tepesi lateralde (humeral) veya medialde (glenoid) olacak şekilde yapılabilir. ${ }^{[1,20]}$ Lateral yaklaşım daha fazla kapsül dokusunun ortaya konulma- 
sı, daha fazla plikasyon yapılmasına imkan sunması ve aksiller sinir yaralanması ihtimalinin daha düşük olması nedeniyle daha avantajlıdır. ${ }^{[21]}$

Kapsülotomi yapıldıktan sonra kapsüler flepler dikkatli bir şekilde humerus boynundan kaldırılır ve posterior kapsüler gevşekliği ve inferior kapsüler poşu ortadan kaldıracak kadar ilerletilir. Kapsüler kaydırmanın miktarı stabilitenin sağlanması, nükslerin önlenmesi ve ameliyat sonrası hareket kısıtıığının minimalize edilmesi açısından büyük önem taşımaktadır. Bu nedenle bu işlem $45^{\circ}$ abduksiyon ve nötral rotasyonda yapilır. ${ }^{[22]}$ Inferior kapsüler flep superior flebin derininde olacak şekilde yeterince superiora kaydırıldıktan sonra 2 numara emilmeyen dikişlerle tespit edilir. Ardından superior flep lateral ve inferiora doğru kaydırılarak kol adduksiyon ve nötral rotasyona alınarak benzer şekilde inferior flebin üstünden tespit edilir. Tenotomi yapıldıysa subskapularis tendonu anatomik lokalizasyona tekrar tespit edilir.

Instabilite cerrahisinin başarısı süregelen korkutma testi pozitifliği, tekrarlayan (rekürren) subluksasyon ve kabul edilmiş fonksiyonel skorlama ölçekleri ve hastanın cerrahi öncesi spor seviyesine geri dönüşüyle değerlendirilir. ${ }^{[4]}$ Bu kriterlere göre yapılmış değerlendirmeler sonucunda, açık inferior kapsüler shift ve Bankart tamiri prosedürünün etkinliği yaklaşık \%95 olarak bildirilmiştir. Ancak bu çalışmalarda spora dönüş seviyesi beklenilenden düşük bulunmuştur. ${ }^{[20,23]}$ Cordasco tarafından yapılan bir derlemede ise açık inferior kapsüler shift prosedürü sonrası hastaların memnuniyet oranının yüksek olduğu ve rekürren instabilite oranının düşük olduğu bildirilmiştir. ${ }^{[21]}$ Longo ve ark. tarafından yapılmış olan bir sistematik derlemede ise dört yıllık takip sonrası tekrar çıkık (redislokasyon) oranı 226 hastada yalnızca \%7,5 olarak bildirilmiştir. ${ }^{[17]}$

Açık inferior kapsüler shift prosedüründe daha önce söylendiği gibi hedef kapsüler plikasyonla eklem hacminin azaltılmasıdır. Eklem hacmindeki azalma, yapılan kapsüler kaydırma miktarıyla orantılıdır. Miller ve ark. yaptıkları çalışmada, farklı kapsüler kaydırma tekniklerini sağladıkları eklem hacmindeki azalma miktarı açısından karşılaştırmışlardır. ${ }^{[24]}$ Lateral (humeral) kapsülotominin medial (glenoid) taraflı kapsülotomiye kıyasla anlamlı olarak fazla hacim azalması sağladığını göstermişlerdir. Açık inferior kapsüler shift tekniğiyle eklem hacminde \%50'ye varan azalma sağlanabildiği bildirilmiştir ancak bunun kliniğe yansıması halen bilinmemektedir. ${ }^{[24,25]}$

\section{ARTROSKOPIK KAPSÜLER PLIKASYON}

Çok yönlü omuz instabilitesi tedavisinde artroskopik teknikler açık tekniklere kıyasla daha az invaziv olması, dinamik stabilizatörlere zarar verilmemesi (açık prosedürlerde subskapularis tenotomisi yapılması ve split geçilmesi gibi), eşlik eden intraartiküler lezyonların tespit edilip bunlara müdahale edilmesi imkanı sunması ve ÇYol'ye spesifik olan gevşemiş ve genişlemiş inferior kapsül gibi kapsülolabral değişimlerin daha iyi görüntülenebilmesi imkanı sunmasından ötürü günümüzde tercih edilen yöntemler haline gelmiştir. ${ }^{[26]}$ Artroskopik tekniklerin bir diğer avantajı ise antero-inferior ve postero-inferior kapsüler genişlemelere tek bir yaklaşımla müdahale edilebilmesi veya her bir bölgeye selektif olarak yaklaşma imkanı sunmasıdır. ${ }^{[4]}$ Posterior labrumda yetmezlik bazı çYoi hastalarında rölatif glenoid retroversiyonuna sebep olarak instabiliteye katkıda bulunabilir. ${ }^{[27]}$ Bu durumun artroskopik olarak görüntülenmesi ve gerekirse labral yapıların augmente edilmesi açık tekniklere göre daha kolaydır. ${ }^{[27]}$

Artroskopik kapsüler plikasyon hasta şezlong veya lateral dekübit pozisyonunda hazırlanarak yapılabilir. İşleme başlamadan önce hasta anestezi altında muayene edilerek instabilitenin yönü ve translasyon miktarı tekrar değerlendirilmelidir. Postero-inferior kapsül ve posterior glenoidin değerlendirilebilmesi amacıyla posterior portal normalden daha laterale açılmalıdır. Tanısal artroskopide tüm intraartiküler yapılar, olası labral lezyonlar ve genişlemiş inferior kapsül sistematik olarak değerlendirilmelidir. Artroskopi esnasında gözlenen drive-through bulgusu kapsüler genişlemenin tipik bulgusudur ${ }^{[26]}$ ve kapsüler plikasyon gereksiniminin göstergesidir (Şekil 1,2). ${ }^{[22]}$

Kapsülün sadece glenoid tarafında değil; aynı zamanda humeral yapışma yerlerinden de değerlendirilmesi önem taşımaktadır. Bu sayede olası bir glenohumeral bağların humeral avülsiyonu (HAGL lezyonu) gözden

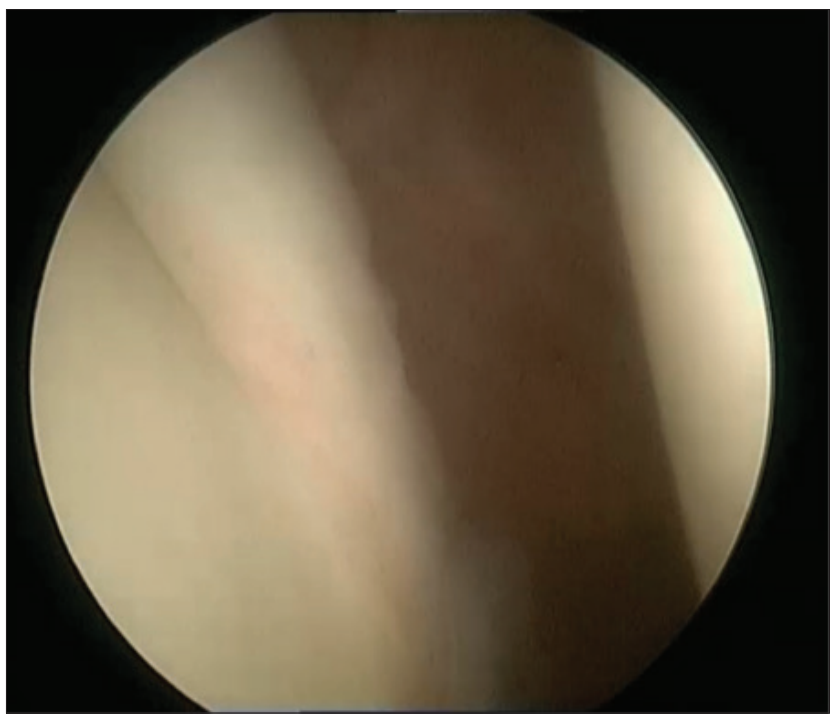

Şekil 1. Glenoid ve humerus arasından optiğin rahatlıkla inferiora geçebilmesi drive through bulgusu. 


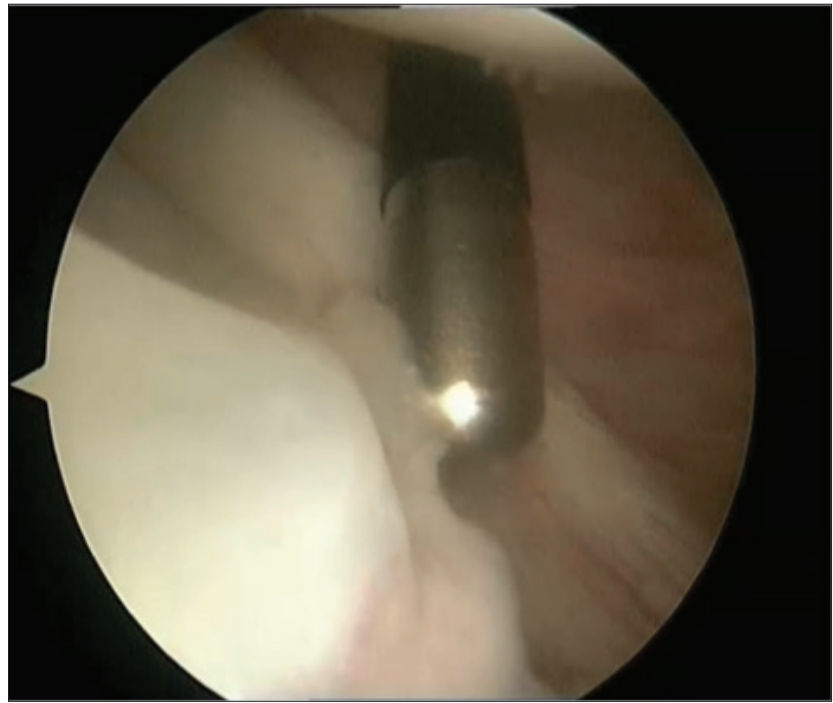

Şekil 2. Glenoid inferior saat 5 pozisyonunda çok ince bir labrum ve gevşek inferior glenohumeral ligaman (IGHL) görünümü.

kaçırılmamış olacaktır. Bunun dışında humerus başı HillSachs lezyonu varlığı açısından değerlendirilmeli ve mevcut lezyonun konumu ve büyüklüğüne göre gerekirse bu lezyonlara da müdahale edilmelidir.

Tanısal artroskopinin ardından antero-superior ve antero-inferior portaller açıır. Posterior portal görüntüleme amacıyla kullanılırken anterior portaller enstrümantasyon için kullanılır. Raspa yardımıyla kapsüler abrazyon yapıldıktan sonra plikasyon işlemine geçilir (Şekil 3).

Kapsüler rekonstrüksiyonun sıralaması iyileşmeyi teşvik etmek için instabilitenin primer yönüne göre belirlenmelidir. ${ }^{[4]}$ Ancak çoğu vakada inferior kapsüler plikasyon gerekeceğinden ve plikasyon yapıldıkça eklem aralığı

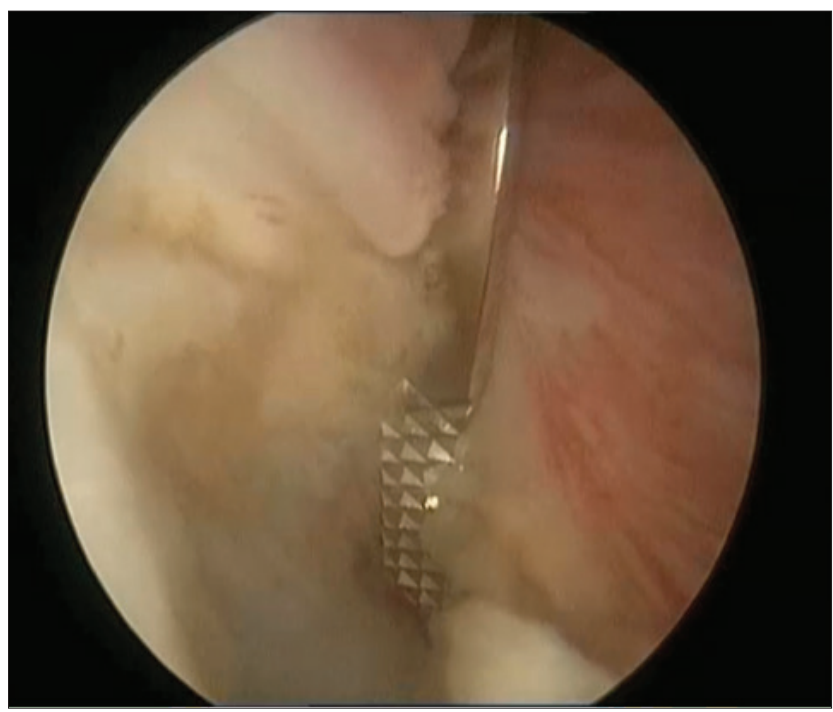

Şekil 3. Labrumun ve IGHL'nin plikasyon için glenoid anterior yüzünden sıyrılması. daralıp görüntüleme ve çalışma alanı azalacağından rekonstrüksiyon inferiordan superiora doğru yapılmalıdır. ${ }^{[28]}$ Böylece hem işlem esnasında görüntüleme daha kolay sağlanır hem de inferior kapsül superiora kaydırılmış olur. Gerektiği durumlarda portaller değiştirilerek anteriordan görüntüleme sağlanabilir.

Labrumun sağlam olması durumunda kapsülden geçirilen sütürlerle kapsül dokusu doğrudan labruma tespit edilebilir. ${ }^{[26]}$ Çünkü sağlıklı labrum dokusunun biyomekanik olarak sütür-ankorla benzer güçte olduğu bildirilmiştir. ${ }^{[29]}$ Ancak labrumun sağlamlığından şüphe ediliyorsa veya labrum intakt değilse sütür-ankor kullanılmalıdır (Şekil 4).

Plikasyon sonrası elde edilen kapsül volüm azalması yapılan plikasyonun sayısı ve büyüklüğüyle orantılıdır. Yapılan çalışmalarda artroskopik kapsüler plikasyon tekniğinin açık kapsüler shift tekniği gibi etkin bir şekilde kapsüler volümü azalttığı gösterilmiştir. ${ }^{[30,31]}$ Flanigan ve ark. yaptıkları kadavra çalışmasında 5 mm'lik kapsüler plikasyonun $\% 16,2 ; 10$ mm'lik plikasyonun ise \%33,7 oranında kapsüler volüm azalması sağladığını göstermiştir. [32] Bir başka kadavra çalışmasında ise çoklu anterior, posterior ve inferior artroskopik plikasyonun açık kapsüler kaydırmadan anlamlı olarak fazla volüm azalması sağladığı gösterilmiştir. ${ }^{[33]}$

Kapsüler volümde azalma sağlanması sadece klinik olarak glenohumeral stabilitede artış sağlaması durumunda fayda sağlamaktadır (Şekil 5).

Yapılan çalışmalarda kapsülolabral augmentasyon ve plikasyonun kapsüler laksiteyi azaltarak ve glenoid konkavitesini derinleştirerek stabiliteyi arttırdığı gösterilmiştir (Şekil 6,7). ${ }^{[34,35]}$

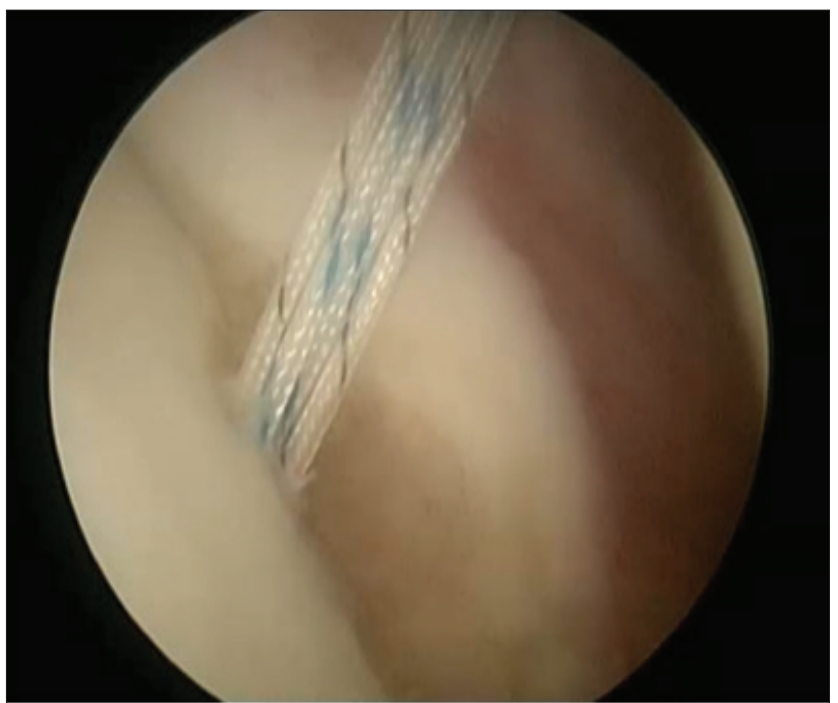

Şekil 4. Plikasyon yapabilmek için glenoid ön kenarına çift yüklü ankorun yerleştirilmesi. 


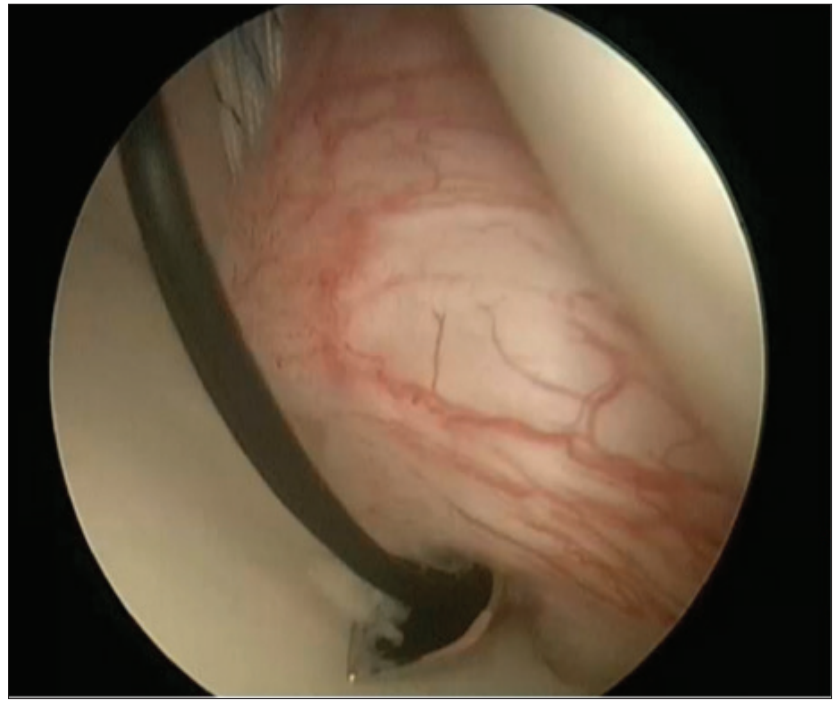

Şekil 5. Kapsül hacmini düşürmek için kapsülden iplerin geçirilmesi.

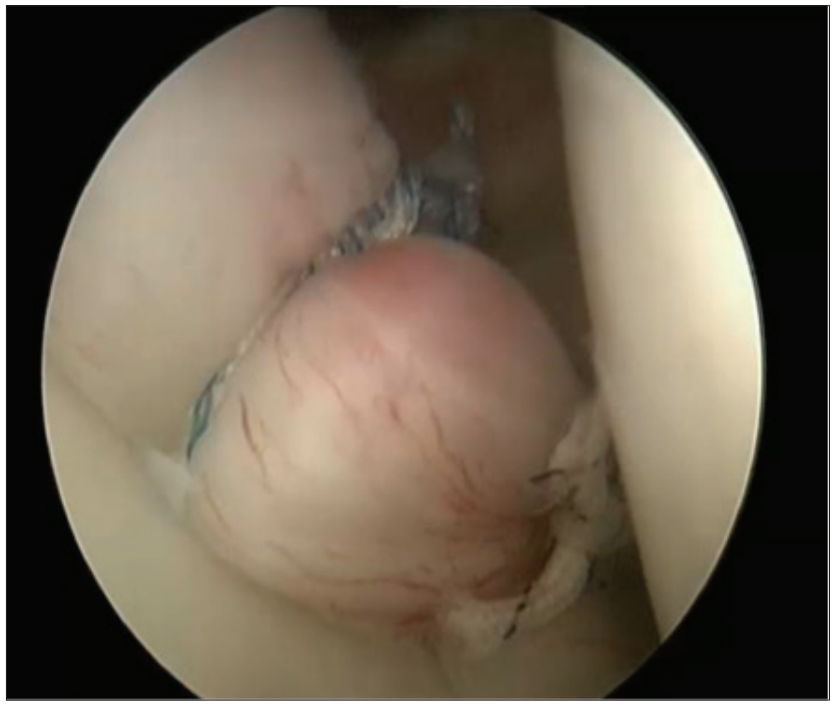

Şekil 6. Plikasyon sonrası labrumun görüntüsü;, ameliyatın başında “+” olan drive through bulgusunun "-" oluşu.

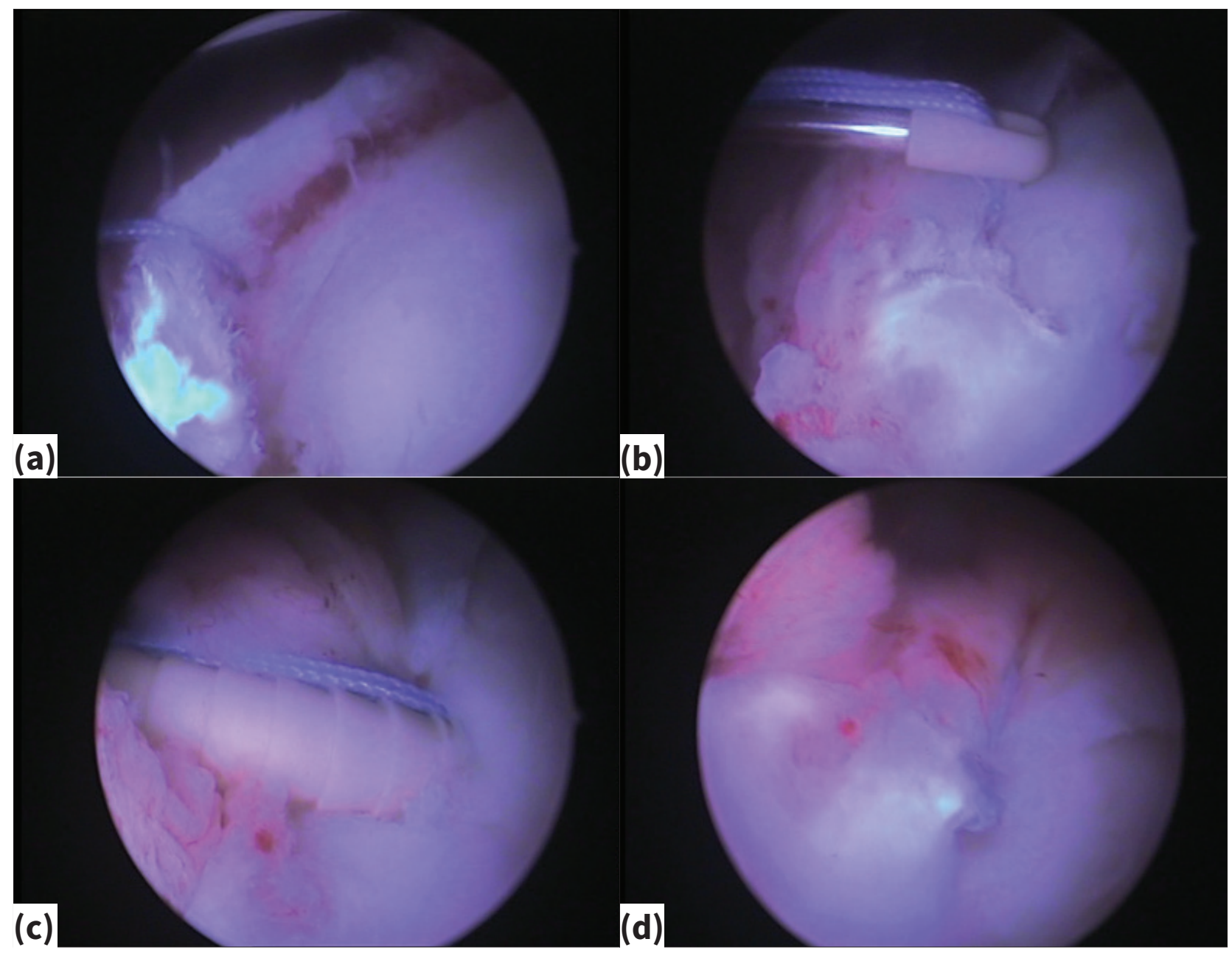

Şekil 7.a-d. Posterior labrumun düğümsüz ankor ile serbest iplik geçirilmesi sonucu glenoid posterioruna plikasyonu. 
Gartsman ve ark. artroskopik olarak tedavi edilmiş 47 ÇYoi hastası ile yaptıkları çalışmalarında hastaların \%94'ünde iyi veya mükemmel sonuç ve fonksiyonel sonuçlarda anlamlı ilerleme göstermişlerdir. ${ }^{[36]}$ Bu çalışmada önemli olarak yazarlar ameliyat sonrası dönemde $\% 85$ oranında istenilen seviyede sportif aktiviteye dönüş bildirmişlerdir. Bir başka çalışmada ise Baker ve ark. benzer klinik sonuçlar ve spora dönüş oranı bildirmiştir. ${ }^{[37]}$ Literatürdeki son bulgular artroskopik tekniğin açık tekniğe kıyasla spora dönüş oranlarında uygun seçilmiş hastalarda daha üstün olabileceği yönündedir. ${ }^{[36-38]}$ Ancak halen bu tekniklerin birbirine karşı üstünlükleri konusunda görüş birliği yoktur. Longo ve ark. tarafından yapılmış olan sistematik derlemede iki tekniğin benzer tekrar çıkık (redislokasyon) oranlarına, ameliyat sonrası dış rotasyon kaybına, spora dönüş oranına ve komplikasyon oranına sahip olduğu gösterilmiştir. ${ }^{[17]}$ Bir başka çalışmada ise Chen ve ark. açık ve artroskopik teknikleri karşılaştırmış; iki tekniğin rekürren instabilite ve tekrar ameliyat (re-operasyon) oranları açısından benzer sonuçları olduğunu ancak açık teknik uygulanan hastalarda dış rotasyon kısıtlılığının daha fazla olduğunu bildirmişlerdir. ${ }^{[16]}$

Kapsüler plikasyon prosedüründe aşırı plikasyon yapılması hareket kısıtlılığına, özellikle dış rotasyon kaybına yol açabilmektedir. ${ }^{[39,40]}$ Bu nedenle plikasyon miktarının uygun belirlenmesi klinik başarı için önem taşımaktadır. Plikasyon miktarının ayarlanması subjektiftir, cerrahın tecrübesine bağlıdır ve her hasta için instabilitenin şiddetine göre bireysel olarak belirlenmelidir. İşlem esnasında karşı tarafla omuz hareketi kıyaslanarak aşırı plikasyon yapmaktan kaçınılmalıdır. ${ }^{[4]}$

\section{SONUÇ}

Çok yönlü omuz instabilitesi, özellikle tanı aşamasında klinisyenler için zorlayıcı olabilen bir patolojidir. Doğru değerlendirme ve tanı sonrasında hastaların büyük bir kısmında rehabilitasyonla yüz güldürücü sonuçlar almak mümkündür. Cerrahi tedavi, uygun rehabilitasyona rağmen semptomların devam ettiği hastalarda endikedir. Cerrahi tedavinin başarısı omuz ekleminin biyomekaniğinin ve glenohumeral eklem instabilitesinin patoanatomisinin doğru anlaşılmasına bağlıdır. Cerrahi kararı ve uygulanacak tekniğin seçimi her hasta için bireysel olarak verilmeli, standart uygulamadan kaçınılmalıdır. Açık inferior kapsüler shift, artroskopik kapsüler plikasyon gibi güncel tekniklerle doğru hasta seçimi ve doğru teknikle iyi sonuçlar elde edilebilmektedir.

\section{KAYNAKLAR}

1. Neer $2^{\text {nd }}$ CS, Foster CR. Inferior capsular shift for involuntary inferior and multidirectional instability of the shoulder. A preliminary report JBJS 1980;62: 897-908. Crossref

2. Lippitt S, Matsen F. Mechanisms of glenohumeral joint stability. Clin Orthop Relat Res 1993;20-8. Crossref

3. Jaggi A, Noorani A, Malone A, Cowan J, Lambert S, Bayley I. Muscle activation patterns in patients with recurrent shoulder instability. Int J Shoulder Surg 2012;6(4):101-7. Crossref

4. Gaskill TR, Millett PJ. Management of multidirectional instability of the shoulder. JAAOS-Journal Am Acad Orthop Surg 2011;19:758-67. Crossref

5. von Eisenhart Rothe R, Mayr HO, Hinterwimmer S, Graichen H. Simultaneous 3D assessment of glenohumeral shape, humeral head centering, and scapular positioning in atraumatic shoulder instability: a magnetic resonance-based in vivo analysis. Am J Sports Med 2010;38(2):375-82. Crossref

6. Matsen FA II, Thomas SC, Rockwood CA Jr, Wirth MA. Glenohumeral instability. In: Rockwood CA Jr, Matsen FA III (eds) The Shoulder, Volume 1. Philadelphia, 2005, pp. 611-754.

7. CS Neer $2^{\text {nd }}$. Involuntary inferior and multidirectional instability of the shoulder: etiology, recognition, and treatment. Instr Course Lect 1985;34:232-8.

8. Burkhead Jr WZ, Rockwood Jr CA. Treatment of instability of the shoulder with an exercise program. JBJS 1992;74:890-6. Crossref

9. Mallon WJ, Speer KP. Multidirectional instability: current concepts. J shoulder Elb Surg 1995;4:54-64. Crossref

10. Guerrero P, Busconi B, Deangelis N, Powers G. Congenital instability of the shoulder joint: assessment and treatment options. J Orthop Sport Phys Ther 2009;39:124-34. Crossref

11. Nyiri P, Illyés Á, Kiss R, Kiss J. Intermediate biomechanical analysis of the effect of physiotherapy only compared with capsular shift and physiotherapy in multidirectional shoulder instability. J shoulder Elb Surg 2010;19:802-13. Crossref

12. Illyés Á, Kiss J, Kiss RM. Electromyographic analysis during pull, forward punch, elevation and overhead throw after conservative treatment or capsular shift at patient with multidirectional shoulder joint instability. J Electromyogr Kinesiol 2009;19:e438-47. Crossref

13. Barden JM, Balyk R, Raso VJ, Moreau M, Bagnall K. Atypical shoulder muscle activation in multidirectional instability. Clin Neurophysiol 2005;116:1846-57. Crossref

14. Schenk TJ, Brems JJ. Multidirectional instability of the shoulder: pathophysiology, diagnosis, and management. JAAOSJournal Am Acad Orthop Surg 1998;6:65-72. Crossref

15. Jacobson ME, Riggenbach M, Wooldridge AN, Bishop JY. Open capsular shift and arthroscopic capsular plication for treatment of multidirectional instability. Arthrosc J Arthrosc Relat Surg 2012;28:1010-7. Crossref 
16. Chen D, Goldberg J, Herald J, Critchley I, Barmare A . Effects of surgical management on multidirectional instability of the shoulder: a meta-analysis. Knee Surgery, Sport Traumatol Arthrosc 2016;24:630-9. Crossref

17. Longo UG, Rizzello G, Loppini M, Locher J, Buchmann S, Maffulli $\mathrm{N}$, et al. Multidirectional instability of the shoulder: a systematic review. Arthrosc J Arthrosc Relat Surg 2015;31:2431-43. Crossref

18. Scheibel M, Habermeyer P. Subscapularis dysfunction following anterior surgical approaches to the shoulder. J shoulder Elb Surg 2008;17:671-83. Crossref

19. Jobe FW, Giangarra CE, Kvitne RS, Glousman RE. Anterior capsulolabral reconstruction of the shoulder in athletes in overhand sports. Am J Sports Med 1991;19:428-34. Crossref

20. Altchek DW, Warren RF, Skyhar Mj, Ortiz G. T-plasty modification of the Bankart procedure for multidirectional instability of the anterior and inferior types. J Bone Joint Surg Am 1991;73:105-12. Crossref

21. Cordasco FA. Understanding multidirectional instability of the shoulder. J Athl Train 2000;35:278.

22. Merolla G, Cerciello S, Chillemi C, Paladini P, De Santis E, Porcellini G. Multidirectional instability of the shoulder: biomechanics, clinical presentation, and treatment strategies. Eur J Orthop Surg Traumatol 2015;25:975-85. Crossref

23. Pollock RG, Owens JM, Flatow EL, Bigliani LU. Operative results of the inferior capsular shift procedure for multidirectional instability of the shoulder. JBJS 2000;82:919-28. Crossref

24. Miller MD, Larsen KM, Luke T, Leis HT, Plancher KD . Anterior capsular shift volume reduction: an in vitro comparison of 3 techniques. J shoulder Elb Surg 2003;12:350-4. Crossref

25. Best MJ, Tanaka MJ. Multidirectional instability of the shoulder: Treatment options and considerations. Sports Med Arthrosc 2018;26:113-9. Crossref

26. Ibán MAR, Heredia JD, Navlet MG, Serrano F, Oliete MS. Suppl6, M2: Multidirectional Shoulder Instability: Treatment. Open Orthop J 2017; 11: 812-25. Crossref

27. Kim S-H, Noh K-C, Park JS, Ryu BD, Oh I. Loss of chondrolabral containment of the glenohumeral joint in atraumatic posteroinferior multidirectional instability. JBJS 2005;87: 92-8. crossref

28. Lee HJ, Kim NR, Moon SG, Ko SM, Park JY . Multidirectional instability of the shoulder: rotator interval dimension and capsular laxity evaluation using MR arthrography. Skeletal Radiol 2013;42:231-8. Crossref

29. Provencher MT, Verma N, Obopilwe E, Rincon LM, Tracy J, Romeo AA, et al. A biomechanical analysis of capsular plication versus anchor repair of the shoulder: can the labrum be used as a suture anchor? Arthrosc J Arthrosc Relat Surg 2008;24:210-6. Crossref
30. Karas SG, Creighton RA, DeMorat GJ. Glenohumeral volume reduction in arthroscopic shoulder reconstruction: a cadaveric analysis of suture plication and thermal capsulorrhaphy. Arthrosc J Arthrosc Relat Surg 2004;20:179-84. Crossref

31. Cohen SB, Wiley W, Goradia VK, Pearson, S, Miller MD. Anterior capsulorrhaphy: an in vitro comparison of volume reductionarthroscopic plication versus open capsular shift. Arthrosc J Arthrosc Relat Surg 2005;21:659-64. Crossref

32. Flanigan DC, Forsythe T, Orwin J, Kaplan L. Volume analysis of arthroscopic capsular shift. Arthrosc J Arthrosc Relat Surg 2006;22:528-33. Crossref

33. Sekiya JK, Willobee JA, Miller MD, Hickman AJ, Willobee A. Arthroscopic multi-pleated capsular plication compared with open inferior capsular shift for reduction of shoulder volume in a cadaveric model. Arthrosc J Arthrosc Relat Surg 2007;23:1145-51. Crossref

34. Metcalf MH, Pon JD, Harryman II DT, Loutzenheiser T, Sidles JA. Capsulolabral augmentation increases glenohumeral stability in the cadaver shoulder. J shoulder Elb Surg 2001;10:5328. Crossref

35. Kim SH, Kim HK, Sun JI, Park JS, Oh I. Arthroscopic capsulolabroplasty for posteroinferior multidirectional instability of the shoulder. Am J Sports Med 2004;32:594-607. Crossref

36. Gartsman GM, Roddey TS, Hammerman SM. Arthroscopic treatment of multidirectional glenohumeral instability: 2-to 5-year follow-up. Arthrosc J Arthrosc Relat Surg 2001;17:236-43. crossref

37. Baker CL III, Mascarenhas R, Kline AJ, Chhabra A, Pombo MW, Bradley JP. Arthroscopic treatment of multidirectional shoulder instability in athletes: a retrospective analysis of 2-to 5-year clinical outcomes. Am J Sports Med 2009;37:1712-20. Crossref

38. Yeargan SA III, Briggs KK, Horan MP, Black AK, Hawkins RJ, et al. Determinants of patient satisfaction following surgery for multidirectional instability. Orthop 2008;31:647. Crossref

39. Provencher MT, Mologne TS, Hongo M, Zhao K, Tasto JP, An $\mathrm{KN}$. Arthroscopic versus open rotator interval closure: biomechanical evaluation of stability and motion. Arthrosc J Arthrosc Relat Surg 2007;23:583-92. Crossref

40. Farber AJ, ElAttrache NS, Tibone JE, McGarry MH, Lee TQ. Biomechanical analysis comparing a traditional superior-inferior arthroscopic rotator interval closure with a novel medial-lateral technique in a cadaveric multidirectional instability model. Am J Sports Med 2009;37:78-1185. Crossref 